\title{
Impact of tricuspid regurgitation after redo valvular surgery on survival in patients with previous mitral valve replacement
}

\author{
Naoto Fukunaga, MD, Yukikatsu Okada, MD, PhD, Yasunobu Konishi, MD, Takashi Murashita, MD, \\ Hideo Kanemitsu, MD, PhD, and Tadaaki Koyama, MD, PhD
}

Objective: The impact on survival of tricuspid regurgitation (TR) after redo valvular surgery in patients with previous mitral valve replacement (MVR) is unclear.

Methods: We retrospectively analyzed 118 consecutive patients undergoing redo valvular surgery after MVR over a 20-year period. We determined the impact of TR after redo valvular surgery on survival and clinical factors that were associated with TR of $2+$ or higher. The mean follow-up period was $7.1 \pm 6.5$ years.

\begin{abstract}
Results: Overall hospital mortality was $8.5 \%$ (10 of 118). Logistic regression analysis revealed that cardiopulmonary bypass duration (odds ratio, $1.025 ; P=.0270$ ) was an independent risk factor for hospital death. There were 25 late deaths. Survival after 5, 10, and 15 years was $77.5 \% \pm 4.2 \%, 68.5 \% \pm 5.1 \%$, and $58.8 \% \pm 6.3 \%$, respectively. Multivariate Cox regression analysis showed that TR less than $2+$ at discharge was a predictor of late survival (hazard ratio, $0.043 ; P<.0382$ ), whereas age, female sex, left ventricular end-diastolic dimension, and cardiopulmonary bypass duration were predictors of late death. Survival for patients with TR less than $2+$ versus $2+$ or higher after redo surgery were $91.4 \% \pm 3.4 \%$ versus $59.5 \% \pm 11.9 \%$ at 5 years and $81.1 \% \pm$ $5.3 \%$ versus $52.1 \% \pm 12.5 \%$ at 10 years, respectively (log-rank $P=.0285$ ). Logistic regression analysis indicated that preoperative TR (odds ratio, 3.718; $P=.0044$ ) and chronic obstructive pulmonary disease (odds ratio, 28.576; $P=.0154$ ) were independent risk factors for TR of $2+$ or higher after redo surgery.

Conclusions: Survival in patients with TR of $2+$ or higher after redo valvular surgery was poor. The results of this study suggest that it is important to maintain a postoperative TR less than $2+$ to improve long-term survival. (J Thorac Cardiovasc Surg 2014;148:1983-8)
\end{abstract}

Late tricuspid regurgitation (TR) after mitral valve replacement (MVR) is a significant problem for cardiac surgeons. Although functional TR might improve after surgical correction of left-sided valve lesions, ${ }^{1}$ residual significant TR has been reported to progress in about half of patients. ${ }^{2}$ TR has harmful effects on clinical outcomes including biventricular heart failure and long-term survival. ${ }^{3}$ Furthermore, 1 report showed that moderate or greater TR is associated with worse survival regardless of left ventricular ejection fraction or increased pulmonary artery pressure. ${ }^{4}$

Tricuspid valve surgery (TVS) as a reoperation carries high operative mortality. Pfannmuller and colleagues ${ }^{5}$ reported that the overall 30-day mortality was $14.6 \%$ and the 2-year survival was $63.0 \% \pm 5.5 \%{ }^{5}$ McCarthy and colleagues ${ }^{6}$ found that 30 -day mortality after reoperation was $32 \%$ and survival at 1 and 3 years was $31 \%$ and $19 \%$,

\footnotetext{
From the Department of Cardiovascular surgery, Kobe City Medical Center General Hospital, 2-1-1 Minatojimaminamimachi, Chuo-ku, Kobe, Hyogo, Japan.

Disclosures: Authors have nothing to disclose with regard to commercial support.

Received for publication May 10, 2013; revisions received July 24, 2013; accepted for publication Aug 15, 2013; available ahead of print Feb 7, 2014.

Address for reprints: Naoto Fukunaga, MD, Department of Cardiovascular Surgery, Kobe City Medical Center General Hospital, 2-1-1 Minatojimaminamimachi, Chuo-ku, Kobe, Hyogo 650-0047, Japan (E-mail: naotowakimachi@ hotmail.co.jp). $0022-5223 / \$ 36.00$

Copyright (c) 2014 by The American Association for Thoracic Surgery

http://dx.doi.org/10.1016/j.jtcvs.2013.08.089
}

respectively. These results indicate that redo TVS may be associated with high mortality; thus, it is difficult to make a decision to intervene for TR after valvular surgery.

The impact on survival of TR after redo valvular surgery in patients with previous MVR is unclear. The relative importance of residual TR might differ between a first and second operation.

Therefore, we analyzed our 20-year experience of redo valvular surgery after MVR to determine the impact of TR after redo valvular surgery on early and long-term survival.

\section{PATIENTS AND METHODS}

This study was approved by the institutional review board at our institute.

We analyzed 118 consecutive patients (41 were males [35\%]) undergoing redo valvular surgery at our institute over a 20 -year period from January 1990 to December 2010. We retrospectively reviewed their medical records in accordance with the Society of Thoracic Surgeons guidelines. ${ }^{7}$ In more than $90 \%$ of patients, a single surgeon performed the redo operation.

All patients had undergone MVR with or without aortic valve replacement. Table 1 shows the preoperative characteristics of the patients included in the study. Atrial fibrillation was present in $80(68 \%)$ of patients. Fifty-two (44\%) patients were in New York Heart association (NYHA) functional class III or IV. About $30 \%$ of the patients had undergone previous valvular surgery. Previous operations included single MVR in 104 $(88 \%)$ and MVR plus aortic valve replacement in $14(12 \%)$. The main cause of redo valvular surgery was structural valve deterioration in the mitral position. 


$$
\begin{aligned}
& \text { Abbreviations and Acronyms } \\
& \mathrm{CI}=\text { confidence interval } \\
& \text { COPD }=\text { chronic obstructive pulmonary disease } \\
& \text { MVR }=\text { mitral valve replacement } \\
& \text { NYHA }=\text { New York Heart association } \\
& \mathrm{TR}=\text { tricuspid regurgitation } \\
& \text { TVR = tricuspid valve replacement } \\
& \text { TVS }=\text { tricuspid valve surgery }
\end{aligned}
$$

TR was graded on transthoracic echocardiography as 0 for no regurgitation, $1+$ for mild regurgitation, $2+$ for moderate regurgitation, $3+$ for moderately severe regurgitation, and $4+$ for severe regurgitation. ${ }^{6}$

TR grade as an end point was assessed at discharge not late recurrent TR on transthoracic echocardiography.

\section{Follow-up}

Patients were followed up in the outpatient clinic every 6 or 12 months. The decision for redo surgery was made based on the examination in the outpatient clinic. The mean follow-up period was $7.1 \pm 6.5$ years (range, $0.04-22.3$ years).

\section{Statistical Analysis}

All statistical analyses were performed with StatView version 5.0 software (SAS Institute, Inc, Cary, NC). Categorical variables were analyzed using the $\chi^{2}$ test and are expressed as percentages. Continuous variables were analyzed by Student paired or unpaired $t$ tests and are expressed as the mean \pm standard deviation. The Kaplan-Meier method was used to estimate long-term survival. Univariate analysis was performed using the Fisher exact probability and $t$ tests. Variables with a univariate probability value of 0.2 or less were included in multivariate logistic regression analysis to determine the independent factors for short-term (hospital) survival. Cox regression analysis was also used to identify the predictors of long-term survival.

\section{RESULTS \\ Early Outcomes and Risk Factors for Hospital Mortality}

Overall hospital mortality was $8.5 \%(n=10)$. The causes of hospital death were arrhythmia $(\mathrm{n}=3)$, multiorgan failure $(\mathrm{n}=3)$, low output syndrome $(\mathrm{n}=2)$, bleeding $(\mathrm{n}=1)$, and sepsis $(\mathrm{n}=1)$. The major postoperative complications included exploration for bleeding $(\mathrm{n}=5)$, stroke $(\mathrm{n}=3)$, reintubation $(\mathrm{n}=7)$, ventilator support for 72 hours or longer $(n=12)$, gastrointestinal bleeding $(n=2)$, newly required dialysis $(\mathrm{n}=3)$, and pacemaker implantation $(\mathrm{n}=5)$. The mean intensive care unit stay was $7.1 \pm 13.1$ days.

Logistic regression analysis revealed that cardiopulmonary bypass duration (odds ratio, $1.025 ; P=.0270 ; 95 \%$ confidence interval [CI], 1.003-1.047) was an independent risk factor for hospital mortality (Table 2). NYHA functional class III or IV, chronic obstructive pulmonary disease (COPD), the number of redo surgeries, and pulmonary hypertension were not significant risk factors.

\section{Long-Term Survival}

During a mean follow-up period of $7.1 \pm 6.5$ years (range, 0.04-22.3 years), there were 25 deaths. The cause of death included heart failure $(n=4)$, sudden death $(n=3)$, multiorgan failure $(n=2)$, bleeding $(n=2)$, arrhythmia $(n=1)$, prosthetic valve endocarditis $(\mathrm{n}=1)$, and others $(\mathrm{n}=12)$.

Kaplan-Meier estimates of cumulative survival are shown in Figure 1. Survival at 5, 10, and 15 years was $77.5 \% \pm 4.2 \%, 68.5 \% \pm 5.1 \%$, and $58.8 \% \pm 6.3 \%$, respectively.

Multivariate Cox regression analysis showed that the only predictor of late survival was TR less than $2+$ at discharge (hazard ratio, 0.043; 95\% CI, 0.002-0.843; $P<.0382)$. In contrast, age, female sex, left ventricular end-diastolic dimension, and cardiopulmonary bypass duration were predictors of late death (Table 3).

\section{Survival Based on TR Grade Before Redo Surgery}

To investigate the impact of preoperative TR on survival, we compared survival based on the preoperative grade of TR (Figure 2). Although there was no significant effect of TR grade on survival, increasing severity of TR tended to be associated with worse survival (log-rank $P=.0649$ ).

With regard to TVS for TR, 49 patients underwent TVS in this study. We analyzed the usefulness of TVS for TR in patients with a preoperative grade of TR of $2+$ or higher. There was no significant difference in late survival between patients with and without TVS $(70.4 \% \pm 8.9 \%$ vs $87.8 \% \pm$ $8.1 \%$ at 5 years, $\log$-rank $P=.1054)$.

\section{Survival Based on TR Grade at Discharge After Redo Surgery}

To examine the impact of TR after redo surgery on survival, we compared survival based on TR grade at discharge on transthoracic echocardiography (Figure 3). Increasing TR severity was associated with worse survival (log-rank $P=.0073$ ).

Although we compared postoperative TR $4+(\mathrm{n}=5)$ with TR $2+(\mathrm{n}=19)$ with regard to survival as a subgroup analysis, there was no statistically significant difference in survival between patients with TR $4+$ and $2+$ (log-rank $P=.1225$ ).

Based on these results, the entire study cohort was classified into 2 groups: TR grade at discharge less than $2+$ and $2+$ or higher; long-term survival was compared between the groups.

Survival between the groups with TR less than $2+$ versus TR $2+$ or higher after redo surgery groups was $91.4 \% \pm$ $3.4 \%$ versus $59.5 \% \pm 11.9 \%$ at 5 years and $81.1 \% \pm$ $5.3 \%$ versus $52.1 \% \pm 12.5 \%$ at 10 years, respectively (log-rank $P=.0285$ ) (Figure 4).

The patient characteristics are summarized in Table 4. There were no significant differences between the 2 groups 
TABLE 1. Clinical characteristics of patients $(\mathbf{N}=118)$

\begin{tabular}{lc}
\hline \multicolumn{1}{c}{ Variables } & n $(\%)$ or mean \\
\hline Mean age, y \pm SD & $63.2 \pm 12.6$ \\
Body surface area, $\mathrm{m}^{2} \pm \mathrm{SD}$ & $1.48 \pm 0.16$ \\
Male sex & $41(35)$ \\
Hypertension & $23(19)$ \\
Diabetes mellitus & $17(14)$ \\
Hyperlipidemia & $10(8)$ \\
COPD & $4(3)$ \\
Congestive heart failure & $37(31)$ \\
Peripheral artery diseases & $4(3)$ \\
Stroke & $32(27)$ \\
Hemodialysis & $2(2)$ \\
Liver cirrhosis & $8(7)$ \\
Coronary artery diseases & $4(3)$ \\
Atrial fibrillation & $80(68)$ \\
Pulmonary hypertension & $30(25)$ \\
NYHA class & \\
I/II (\%) & $66(56)$ \\
III/IV (\%) & $52(44)$ \\
Urgency of surgery & \\
Elective (\%) & $105(89)$ \\
Emergency/urgent $(\%)$ & $13(11)$ \\
Number of redo surgery & \\
First time & $80(68)$ \\
Twice or more & $38(32)$ \\
Previous operations & \\
MVR & $104(88)$ \\
$\quad$ Mechanical & $21(18)$ \\
$\quad$ Biological & $83(70)$ \\
Causes of redo & $14(12)$ \\
SVD & \\
Non-SVD & $86(73)$ \\
PVE & $15(13)$ \\
Others & $9(8)$ \\
\hline SD, St & $8(7)$ \\
\hline
\end{tabular}

$S D$, Standard deviation; $C O P D$, chronic obstructive pulmonary disease; $N Y H A$, New York Heart Association; $M V R$, mitral valve replacement; $A V R$, aortic valve replacement; $S V D$, structural valve deterioration; $P V E$, prosthetic valve endocarditis.

except for the body mass index $(P=.0480)$, COPD $(P=.0057)$, and congestive heart failure $(P=.0274)$. TVS was performed in 41 patients $(44 \%)$ with TR less than $2+$ and in $8(33 \%)$ with TR greater than $2+$; the difference was not significant $(P=.3615)$. TVS consisted of

TABLE 2. Multivariate predictors of hospital mortality and tricuspid regurgitation grade of $2+$ or higher at discharge

\begin{tabular}{lccc}
\hline \multicolumn{1}{c}{ Variables } & Odds ratio & $\mathbf{9 5} \%$ CI & $\boldsymbol{P}$ value \\
\hline Hospital mortality & & & \\
$\quad$ CPB duration & 1.025 & $1.003-1.047$ & .0270 \\
TR $\geq 2+$ after redo & & & \\
$\quad$ Preoperative TR & 3.718 & $1.506-9.175$ & .0044 \\
COPD & 28.576 & $1.898-430.3$ & .0154 \\
Congestive heart failure & 6.601 & $0.889-49.014$ & .0650 \\
\hline
\end{tabular}

$C I$, Confidence interval; $C P B$, cardiopulmonary bypass; $T R$, tricuspid regurgitation; $C O P D$, chronic obstructive pulmonary disease.

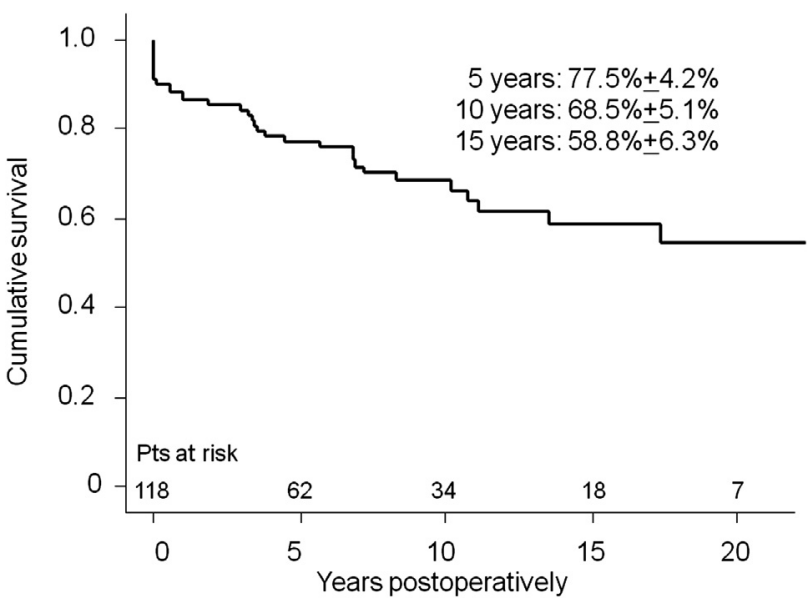

FIGURE 1. Kaplan-Meier curve showing overall survival after redo surgery. Pts, Patients.

annuloplasty performed by either suture or a ring in all 49 patients.

Prosthetic valve endocarditis was more common in the group with TR $2+$ or higher $(P=.0616)$. Preoperative transthoracic echocardiographic data are shown in Table 5. There was a significant difference in the preoperative TR grade between the 2 groups $(P<.0001)$. We also analyzed the risk factors for TR $2+$ or higher after redo surgery. Logistic regression analysis indicated that the preoperative grade of TR (odds ratio, 3.718; $P=.0044$ ) and COPD (odds ratio, 28.576; $P=.0154$ ) were independent risk factors for TR $2+$ or higher. The effect of congestive heart failure on the group with TR $2+$ or higher did not reach statistical significance $(P=.0650)$.

\section{Freedom From Late Recurrent TR $2+$ or Higher}

Late recurrent TR was defined as an increase in TR by more than 1 grade and a final TR grade of $2+$ or higher on late follow-up echocardiography. Patients with a TR grade of $2+$ at both discharge and late follow-up were not included in the group that developed late recurrent TR $2+$ or higher. Freedom from late recurrent TR $2+$ or higher was $91.5 \% \pm 3.7 \%$ at 5 years and $73.2 \% \pm 6.5 \%$ at 10 years. Freedom from late recurrent TR $2+$ or higher at 5 years in patients undergoing De Vega and ring annuloplasty

TABLE 3. Multivariate Cox regression analysis for risk factor of late death

\begin{tabular}{lccc}
\hline \multicolumn{1}{c}{ Variables } & Hazard ratio & $\mathbf{9 5} \% \mathbf{C I}$ & $\boldsymbol{P}$ value \\
\hline Age & 1.741 & $1.257-2.411$ & .0008 \\
Female & 22.182 & $2.353-209.1$ & .0068 \\
LVEDD at discharge & 1.706 & $1.194-2.437$ & .0034 \\
CPB duration & 1.084 & $1.015-1.158$ & .0166 \\
TR $<2+$ at discharge & 0.043 & $0.002-0.843$ & .0382 \\
\hline
\end{tabular}

$C I$, Confidence interval; $L V E D D$, left ventricular end-diastolic diameter; $C P B$, cardiopulmonary bypass; $T R$, tricuspid regurgitation. 


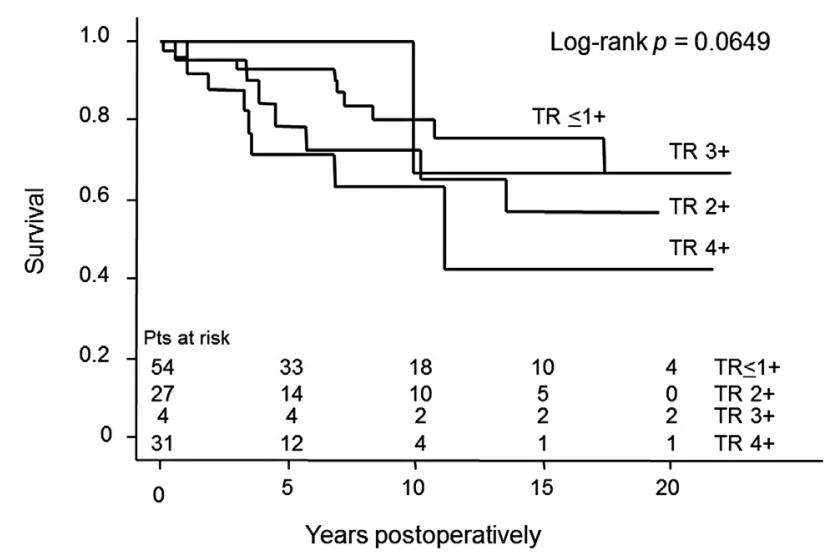

FIGURE 2. Kaplan-Meier curve showing survival based on the grade of tricuspid regurgitation before redo surgery. Pts, Patients; TR, tricuspid regurgitation.

was $75.0 \% \pm 15.3 \%$ and $85.6 \% \pm 9.5 \%$, respectively (log-rank $P>.05$ ).

\section{DISCUSSION}

The present study describes the negative impact of a TR grade of $2+$ or higher after redo valvular surgery on longterm survival in patients with previous MVR. Nath and colleagues ${ }^{4}$ found that TR $2+$ or higher was associated with worse survival in a general cohort. Given our results, the findings of Nath and colleagues ${ }^{4}$ may also apply to patients who have undergone redo valvular surgery.

The negative impact of TR grade of $2+$ or higher suggests that there should be aggressive management of TR after redo valvular surgery to achieve a TR grade less than $2+$.

In our cohort, the risk factors for TR $2+$ or higher after redo surgery were preoperative TR grade and COPD. A relationship between COPD and pulmonary hypertension has been described previously. ${ }^{8}$ Furthermore, pulmonary hypertension is an important factor that affects functional

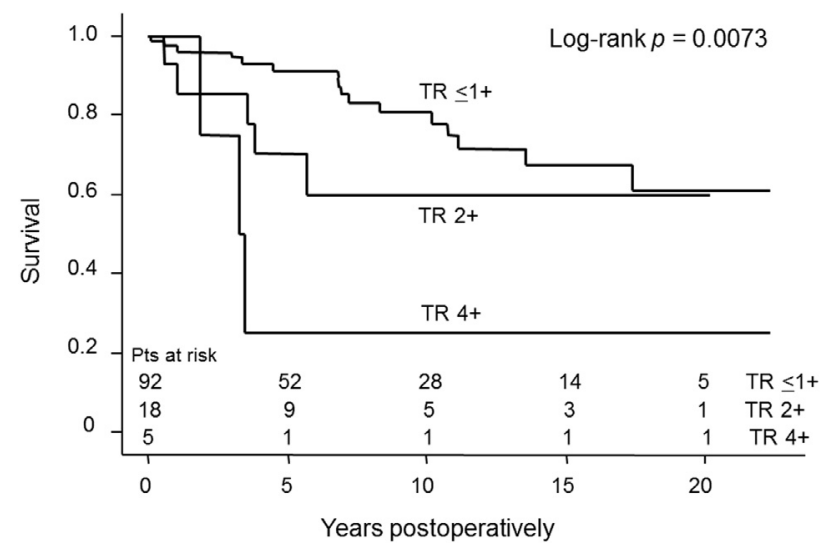

FIGURE 3. Kaplan-Meier curve showing survival based on the grade of tricuspid regurgitation after redo surgery. Pts, Patients; TR, tricuspid regurgitation.

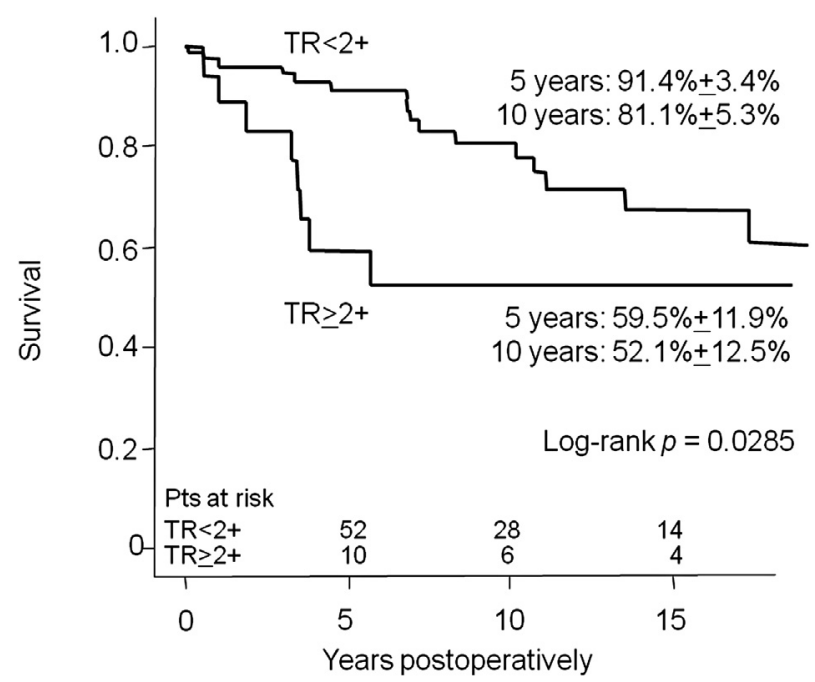

FIGURE 4. Kaplan-Meier curves comparing survival between patients with tricuspid regurgitation less than $2+$ and $2+$ or higher after redo surgery. Pts, Patients; TR, tricuspid regurgitation.

TR. ${ }^{9}$ However, our analysis did not identify pulmonary hypertension as an independent factor for functional TR.

In our current strategy for treating functional TR, ring annuloplasty is a mandatory procedure. The selection of ring size is based on the patients' body surface area. However, if residual massive TR is recognized on intraoperative transesophageal echocardiography, additional or alternative procedures might be necessary.

One option to manage residual TR is to perform tricuspid valve replacement (TVR). In our 20-year experience, TVR was performed in a few cases and postoperative TR was moderate or less. Another option is to perform leaflet repair. We have reported a technique of leaflet augmentation by glutaraldehyde-treated autologous pericardium for late TR after cardiac surgery. ${ }^{10}$ This procedure is useful to prevent postoperative TR $2+$ or higher.

The 5-year survival after TVR was $60 \% \pm 13 \%$ for mechanical valves and $56 \% \pm 6 \%$ for bioprosthetic valves $(P=.8) .{ }^{11}$ Survival for tricuspid valve repair compared with TVR for late TR was $84.1 \%$ versus $69.4 \%$ after 1 year and $84.1 \%$ versus $60.1 \%$ after 3 years, respectively (log-rank $P=.043) .{ }^{12}$ Early and late outcomes for tricuspid valve repair were better than those for TVR. On the other hand, there was no significant difference in 10-year survival between TVR and repair. ${ }^{13}$ Freedom from reoperation at 5 years occurred in more than $90 \%$ of patients with TVR. ${ }^{11}$ Over our 20-year experience, TVR was performed in only a few cases in our institute, but TVR itself did not necessarily have worse outcomes. In specific cases such as stenotic tricuspid valve, a history of previous TVS, dilated right ventricle, right ventricular dysfunction, and repeated cardiac surgery, TVR was indicated. ${ }^{3}$ It might be acceptable to perform TVR in those cases to maintain TR grade at less than $2+$ after redo surgery as mentioned earlier. 
TABLE 4. Comparison between tricuspid regurgitation grade less than 2 and $2+$ or higher after redo surgery

\begin{tabular}{|c|c|c|c|}
\hline Variables & $\begin{array}{c}\text { TR }<2+(\mathbf{n}=\mathbf{9 4}), \\
\mathbf{n}(\%)\end{array}$ & $\begin{array}{c}\mathbf{T R} \geq \mathbf{2}+(\mathbf{n}=\mathbf{2 4}), \\
\mathbf{n}(\%)\end{array}$ & $P$ value \\
\hline Mean age, $\mathrm{y} \pm \mathrm{SD}$ & $62.7 \pm 13.1$ & $65.5 \pm 9.9$ & .1687 \\
\hline $\mathrm{BSA}, \mathrm{m}^{2} \pm \mathrm{SD}$ & $1.48 \pm 0.16$ & $1.47 \pm 0.18$ & .0480 \\
\hline Male sex & $32(34)$ & $9(38)$ & .7509 \\
\hline Hypertension & $19(20)$ & $4(17)$ & .6955 \\
\hline Diabetes mellitus & $13(14)$ & $4(17)$ & .7829 \\
\hline Hyperlipidemia & $8(9)$ & $2(8)$ & .9778 \\
\hline COPD & $1(1)$ & $3(13)$ & .0057 \\
\hline $\begin{array}{l}\text { Congestive heart } \\
\text { failure }\end{array}$ & $25(27)$ & $12(50)$ & .0274 \\
\hline PAD & $3(3)$ & $1(4)$ & .8137 \\
\hline Stroke & $27(29)$ & $5(21)$ & .4377 \\
\hline Hemodialysis & $1(1)$ & $1(4)$ & .2932 \\
\hline Liver cirrhosis & $7(7)$ & $1(4)$ & .5683 \\
\hline $\mathrm{CAD}$ & $4(4)$ & $0(0)$ & .3039 \\
\hline Atrial fibrillation & $61(65)$ & $19(79)$ & .1817 \\
\hline NYHA class III/IV & $38(40)$ & $14(58)$ & .1148 \\
\hline Emergency & $11(12)$ & $2(8)$ & .6380 \\
\hline $\begin{array}{l}\text { Number of redo } \\
\text { twice or more }\end{array}$ & $27(29)$ & $11(46)$ & .1094 \\
\hline \multicolumn{4}{|l|}{ Previous operations } \\
\hline MVR & $84(89)$ & $20(83)$ & .4150 \\
\hline $\mathrm{MVR}+\mathrm{AVR}$ & $10(11)$ & $4(17)$ & .4150 \\
\hline \multicolumn{4}{|l|}{ Causes of redo } \\
\hline SVD & $69(73)$ & $17(71)$ & .8004 \\
\hline Non-SVD & $13(14)$ & $2(8)$ & .4706 \\
\hline PVE & $5(5)$ & $4(17)$ & .0616 \\
\hline \multicolumn{4}{|l|}{ Current operations } \\
\hline MVR & $78(83)$ & $22(92)$ & .2907 \\
\hline AVR & $3(3)$ & $1(4)$ & .8137 \\
\hline $\mathrm{MVR}+\mathrm{AVR}$ & $12(13)$ & $0(0)$ & .0648 \\
\hline TVS & $41(44)$ & $8(33)$ & .3615 \\
\hline Suture & 19 & 4 & \\
\hline Ring & 22 & 4 & \\
\hline
\end{tabular}

$T R$, Tricuspid regurgitation; $S D$, standard deviation; $B S A$, body surface area; $C O P D$, chronic obstructive pulmonary disease; $P A D$, peripheral artery disease; $C A D$, coronary artery disease; NYHA, New York Heart Association; $M V R$, mitral valve replacement; $A V R$, aortic valve replacement; $S V D$, structural valve deterioration; $P V E$, prosthetic valve endocarditis; TVS, tricuspid valve surgery.

With regard to the method of annuloplasty, McCarthy and colleagues ${ }^{6}$ concluded that TR increased over time after Peri-Guard and De Vega annuloplasty, and these techniques

TABLE 5. Preoperative transthoracic echocardiographic data

\begin{tabular}{lccr}
\hline \multicolumn{1}{c}{ Variables } & TR $<\mathbf{2}+(\mathbf{n}=\mathbf{9 4})$ & TR $\geq \mathbf{2}+(\mathbf{n}=\mathbf{2 4})$ & $\boldsymbol{P}$ value \\
\hline LVEF, $\% \pm$ SD & $61.6 \pm 8.8$ & $57.9 \pm 8.9$ & .7842 \\
LVEDD, mm \pm SD & $45.8 \pm 6.5$ & $45.8 \pm 7.9$ & .9032 \\
LVESD, mm \pm SD & $29.5 \pm 7.1$ & $29.0 \pm 6.8$ & .3017 \\
LAD, $\mathrm{mm} \pm \mathrm{SD}$ & $49.6 \pm 12.9$ & $46.3 \pm 12.8$ & .6346 \\
RVP, $\mathrm{mm} \mathrm{Hg} \pm \mathrm{SD}$ & $46.2 \pm 16.2$ & $45.6 \pm 11.1$ & .8673 \\
TR grade \pm SD & $1.6 \pm 1.0$ & $2.4 \pm 0.6$ & $<.0001$ \\
\hline
\end{tabular}

$T R$, Tricuspid regurgitation; $S D$, standard deviation; $L V E F$, left ventricular ejection fraction; $L V E D D$, left ventricular end-diastolic diameter; $L V E S D$, left ventricular end-systolic diameter; $L A D$, left atrium diameter; $R V P$, right ventricular pressure. should be abandoned. Other review papers have also indicated that ring annuloplasty is superior to De Vega annuloplasty. ${ }^{14}$ Given this evidence and the reproducibility of ring annuloplasty, artificial ring annuloplasty is an important surgical option for TVS. In our study, all 49 patients $(42 \%)$ who underwent TVS had tricuspid annuloplasty at the time of redo surgery. Of these, 23 (47\%) underwent annuloplasty using the suture technique.

Fukuda and colleagues ${ }^{15}$ demonstrated the value of the tricuspid annulus area in healthy individuals. They reported that both the maximum and minimum tricuspid annulus areas in patients with TR $2+$ or higher were larger than those values in healthy individuals $(P<.05)$.

Inappropriate ring size selection, which ignores the relationship between body surface area and tricuspid annulus area as shown by Fukuda and colleagues ${ }^{15}$ might be related to a TR grade of $2+$ or higher after redo surgery, leading to poor long-term survival. In our institute, the prosthetic ring size is selected based on the patient's body surface area.

Redo TVS was associated with worse clinical outcomes. Some studies reported high mortality rates ranging from $13.2 \%$ to $37 \%$. $5,6,16$

Despite the high mortality rate, survivors benefited from redo surgery and NYHA class at follow-up was better than that preoperatively. ${ }^{16}$ Mortality in elective surgery was much lower than that in emergency surgery $(4.0 \%$ vs $31.2 \% ; P=.001) .{ }^{5}$ Park and colleagues ${ }^{3}$ reported no hospital deaths after redo TVS. Possible reasons for this favorable outcome were younger patients compared with previous reports and the use of aggressive hemofiltration. Overall in-hospital mortality in our study was $9.4 \%$, which was lower than that reported previously.

Isolated TVS with minimally invasive access via a right thoracotomy has been increasingly applied in redo surgery. An early mortality rate of $4.2 \%$ was reported using this technique. In particular, the mortality rate in elective cases was $0 \%{ }^{16}$

The investigators stated that with this technique there is no need to dissolve adhesions and scar tissue to cannulate vessels for cardiopulmonary bypass, and this may reduce the incidence of right-sided dilatation and failure that can accompany traditional open surgery. ${ }^{5,17}$

In redo TVS, most patients referred for surgery have advanced heart failure or end-organ dysfunction. ${ }^{16}$ The high mortality and morbidity in redo TVS is believed to be associated with not only redo TVS itself but also endorgan dysfunction. It is reasonable to think that surgical intervention should be earlier rather than later. ${ }^{17}$ It has been suggested that significant TR should be operated on before there is irreversible damage to the right ventricle in patients with advanced mitral valve disease. ${ }^{3,18}$

Predictors of early death in a previous study included advanced age, creatinine levels of $2 \mathrm{mg} / \mathrm{dL}$ or higher and Child-Pugh C liver cirrhosis. ${ }^{12}$ In our study, cardiopulmonary 
bypass duration was identified as a risk factor for hospital mortality and late death. This result possibly reflects operative injury to patients because patients who underwent TVS as a redo surgery had lower organ reserve as mentioned earlier.

The reason for the worse long-term mortality in patients with significant TR is possibly because TR is a more sensitive marker of right ventricular dysfunction than visual interpretation of systolic performance, and the presence of TR may mask decreased contractility of the right ventricle. ${ }^{4}$ Right ventricular function is an important factor affecting midterm and long-term survival in patients with valvular diseases. $^{18}$

In our study, total cumulative survival at 5, 10 and 15 years was $77.5 \% \pm 4.2 \%, 68.5 \% \pm 5.1 \%$, and $58.8 \% \pm$ $6.3 \%$, respectively.

Survival of patients with TR less than $2+$ and $2+$ or higher after redo surgery was $91.4 \% \pm 3.4 \%$ versus $59.5 \% \pm 11.9 \%$ at 5 years and $81.1 \% \pm 5.3 \%$ versus $52.1 \% \pm 12.5 \%$ at 10 years (log-rank $P=.0285)$. These results show the negative impact of TR, in particular a TR grade of $2+$ or higher on survival. Because no previous studies have reported the effect of TR $2+$ or higher on survival after redo surgery, we could not compare our results with previous reports. Park and colleagues ${ }^{3}$ reported that survival at 5 years was $93 \%$ for both TVR and tricuspid repair. Chen and colleagues ${ }^{12}$ reported 3-year survival of $76.4 \%$ after TVS. Despite differences in patients' backgrounds, survival in patients with TR $2+$ or higher after redo surgery in the present study was worse compared with the outcomes in these previous studies.

\section{Limitations}

The present study has been some important limitations. It was a retrospective study rather than a randomized trial. Because surgical indications and techniques such as suture and ring annuloplasty for TR after MVR were not uniform, TVS was not performed in some patients with a preoperative TR grade of $2+$ or higher. This fact might have affected postoperative TR and long-term survival.

However, we included a relatively large number of patients $(\mathrm{n}=118)$ who underwent redo valvular surgery after MVR and had a long duration of follow-up. In addition, no previous studies have described the impact of TR after redo surgery on survival. Therefore, our study provides important information not only for cardiac surgeons but also for cardiologists regarding the negative impact of TR after redo valvular surgery on survival. Our results draw attention to the presence of TR in redo surgery in the setting of currently available transcatheter aortic valve implantation techniques.

\section{CONCLUSIONS}

Survival in patients with a TR grade of $2+$ or higher after redo surgery was poor. The appropriate management of TR postoperatively may improve long-term survival. For patients with multiple risk factors for the development of TR 2+ or higher after redo valvular surgery, surgical interventions should be considered at the time of redo surgery to prevent postoperative TR $2+$ or higher.

\section{References}

1. Braunwald NS, Ross J Jr, Morrow AG. Conservative management of tricuspid regurgitation in patients undergoing mitral valve replacement. Circulation. 1967;35:I63-9.

2. Dreyfus GD, Gorbi PJ, Chan KM, Bahrami T. Secondary tricuspid regurgitation or dilatation: which should be the criteria for surgical repair? Ann Thorac Surg. 2005;79:127-32.

3. Park CK, Park PW, Sung K, Lee YT, Kim WS, Jun TG. Early and midterm outcomes for tricuspid valve surgery after left-sided valve surgery. Ann Thorac Surg. 2009;88:1216-23.

4. Nath J, Foster E, Heidenreich PA. Impact of tricuspid regurgitation on long-term survival. J Am Coll Cardiol. 2004;43:405-9.

5. Pfannmuller B, Moz M, Misfeld M, Borger MA, Funkat AK, Garbade J, et al Isolated tricuspid valve surgery in patients with previous cardiac surgery. J Thorac Cardiovasc Surg. 2013;146:841-7.

6. McCarthy PM, Bhudia SK, Rajeswaran J, Hoercher KJ, Ltyle BW Cosgrove DM, et al. Tricuspid valve repair: durability and risk factors for failure. J Thorac Cardiovasc Surg. 2004;127:674-85.

7. Akins CW, Miller C, Turina MI, Kouchoukos NT, Blackstone EH, Grunkemeier GL, et al. Guidelines for reporting mortality and morbidity after cardiac valve interventions. Ann Thorac Surg. 2008;85:1490-5.

8. Held M, Jany B. Pulmonary hypertension in COPD. Respir Care. 2013;58: e86-91.

9. Mutlak D, Aronson D, Lessick J, Reisner SA, Dabbah S, Agmon Y. Functional tricuspid regurgitation in patients with pulmonary hypertension: is pulmonary artery pressure the only determinant of regurgitation severity? Chest. 2009; 135:115-21.

10. Murashita T, Okada Y, Nasu M, Fujiwara H, Koyama T, Shomura Y, et al. Tricuspid leaflet augmentation with an autologous pericardial patch for recurrent severe tricuspid regurgitation that occurred after suture annuloplasty. Surg Today. 2013;43:341-4.

11. Carrier M, Hebert Y, Pellerin M, Bouchard D, Perrault LP, Cartier R, et al. Tricuspid valve replacement: an analysis of 25 years of experience at a single center. Ann Thorac Surg. 2003;75:47-50.

12. Chen SW, Tsai FC, Tsai FC, Chao YK, Huang YK, Chu JJ, et al. Surgical risk and outcome of repair versus replacement for late tricuspid regurgitation in redo operation. Ann Thorac Surg. 2012;93:770-5.

13. Jeong DS, Park PW, Mwnmbu TP, Sung K, Kim WS, Lee YT, et al. Tricuspid re operation after left-sided rheumatic valve operations. Ann Thorac Surg. 2013;95: 2007-14.

14. Khorsandi M, Banerjee A, Singh H, Srivastava AR. Is a tricuspid annuloplasty ring significantly better than a De Vega's annuloplasty stitch when repairing severe tricuspid regurgitation. Interact Cardiovasc Thorac Surg. 2012;15: 129-35.

15. Fukuda S, Saracino G, Matsumura Y, Daimon M, Tran H, Greenberg NL, et al. Three-dimensional geometry of the tricuspid annulus in healthy subjects and in patients with functional tricuspid regurgitation: a real-time, 3-dimensional echocardiographic study. Circulation. 2006;114(suppl I):I-492-8.

16. Jeganathan R, Armstrong S, Al-Alao B, David T. The risk and outcomes of reoperative tricuspid valve surgery. Ann Thorac Surg. 2013;95:119-24.

17. Pfannmuller B, Misfeld M, Borger MA, Etz CD, Funkat AK, Garbade J, et al Isolated reoperative minimally invasive tricuspid valve operations. Ann Thorac Surg. 2012;94:2005-10.

18. Nagel E, Stuber M, Hess OM. Importance of the right ventricle in valvular heart disease. Eur Heart J. 1996;17:829-36. 